\title{
Proceeding
}

Supplementary Issue: Spring Conferences of Sports Science. International Conference on Psychology of Education Sciences \& Lifestyle.

\section{Study of students' cognitive states self-regulation during lessons}

\author{
ALISA R. KHALFIEVA $\triangle$, MARK G. YUSUPOV \\ Department of General Psychology, Kazan (Volga Region) Federal University, Kazan, Russian Federation
}

\begin{abstract}
The relevance of the study of that problem is associated with an increase in information loads on students in connection with the academic load in a situation of information oversaturation. The modern conditions require more and more adaptation to stressful situations, as well as the many stressful factors that students are exposed to both in ordinary life and in the situation of educational activities. In this regard, this article is aimed to study selfregulation in the process of educational activity, namely during lectures, seminars and passing exams/tests. The leading method of the study of this paper is the questionnaire method, conducted among 81 students of the Kazan Federal University for the Humanities and Natural Sciences, which made it possible to identify the most pronounced cognitive states of students during various types of study process. The questionnaire also made it possible to familiarize themselves with their methods of self-regulation of cognitive mental states and obstacles, difficulties in using self-regulation methods. The article shows that students during lecture and seminar training experience the same state of interest and reflection. The difference is that during the lecture classes for students, a cognitive state of curiosity is added to these states, and at a seminar focus. In the tests, students are mostly only in a state of concentration. The article also shows that students most often use self-regulation techniques in seminar-type training sessions. Students resort to various methods of self-regulation: such as forcing oneself to concentrate on a task, a technique, on the contrary, abstracting oneself, as well as using physical exercises, breathing techniques, etc. The materials presented in that article can be used in the development of work programs of academic disciplines implemented within the framework of higher education, in the preparation of training classes of lecture and seminar types, as well as when working with students to increase their effectiveness during the educational process. The scientific novelty of this research consists in the presentation of a technologies of students' cognitive mental states self-regulation during educational process.

Keywords: Students; Training sessions; Self-regulation; Cognitive states; Lectures; Seminars; Educational process.

Cite this article as:

Khalfieva, A.R., \& Yusupov, M.G. (2020). Study of students' cognitive states self-regulation during lessons. Journal of Human Sport and Exercise, 15(3proc), S898-S906. doi:https://doi.org/10.14198/jhse.2020.15.Proc3.41

Corresponding author. Department of General Psychology, Kazan (Volga Region) Federal University, Kazan, Russian Federation.

E-mail: khalfieva@inbox.ru

Supplementary Issue: Spring Conferences of Sports Science. International Conference on Psychology of Education Sciences and Lifestyle.

JOURNAL OF HUMAN SPORT \& EXERCISE ISSN 1988-5202

(c) Faculty of Education. University of Alicante

doi:10.14198/jhse.2020.15.Proc3.41
\end{abstract}

S898

| 2020 | Proc3 | VOLUME 15

(C) 2020 University of Alicante 


\section{INTRODUCTION}

\section{The relevance of the study}

Today, in conditions of rapidly developing digital technologies, in a situation of information and emotional stress, uncertainty and, at the same time, multitasking, the topics of self-regulation, development of abilities to manage one's own resources, and establishing a balance between external influences, internal states, and behaviours are becoming relevant. Every day, increasing factors of informational and emotional stress on a person further aggravate the need to develop and improve this ability. The possibilities of personality self-regulation, its adequate response to various external influences, and the management of the diversity of its mental states are becoming increasingly relevant for the category of students studying at universities. As the studies of the team of authors and scientists of Kazan (Volga region) Federal University, engaged in the study of human mental states within the framework of Kazan Psychological School, show that cognitive states are a special category that requires special study, since the efficiency and success of the educational process depends on them. Therefore, studies of self-regulation of cognitive states, for their further more conscious application by participants in the educational process, are becoming highly relevant.

\section{Literature review}

Cognitive states are one of the types of a person's mental states, integrating those mental processes and properties that a person needs in his life for the effective implementation of cognitive tasks. These states accompany the process of cognition (Levitov, 1964). Cognitive states are associated with the activity of metacognitive processes and perform the function of organizing and regulating cognitive activity (Prokhorov \& Yusupov, 2014a,b). According to the literature analysis on the study topic showed that self-regulation in everyday life is associated with the person's position in the process of adaptation (Hartmann, 2002), with the harmonization of the functional systems of body and psyche, the desire for an equilibrium state, a decrease in the mismatch of functional connections (Bodrov, 2007), as well as with solving problems (Dikaya, 2003), conscious self-regulation (Konopkin, 2007; Morosanova, Fomina \& Tsyganov, 2017), controlling behaviour (Sergienko, 2009), establishing regulatory experience (Osnitsky, 2011) and etc.

According to A.O. Prokhorov (2017) works the regulatory process is carried out in a specific social environment against the background of cultural, ethnic, professional and other influences, in a certain social situation of life: economic, legal, associated with the subject's place in a small group - his social roles, statuses, etc. The deployment of a functional complex of conditions, and also its parameters and their changes in everyday situations of life are determined by the requirements of the social functioning of the subject, the specifics of professional activity and attitude to it, as well as individual and personal characteristics (Prokhorov, 2017).

\section{Current trends in the study of problem}

The analysis of modern literature shows that the place and role of cognitive states in the process of professional training of future specialists is practically not taken into account, therefore studies of cognitive states at the "student age" are relevant, because this particular age period is characterized by a high potential for personal and professional development (Prokhorov \& Yusupov, 2014a,b). Regarding the features and patterns of self-regulation of states in the daily life of the subject, and especially the subject of the educational process, they can be described from the standpoint of a system-functional concept of mental states selfregulation (Prokhorov, 2005; Prokhorov \& Larionova, 2007). 


\section{METHODS}

\section{Purpose of the study}

Because of the relevance of studying problem and its insufficient elaboration, two purposes were set. Firstly, the study of the most pronounced cognitive states during lecture, seminar-type training sessions, as well as during exams / tests. Secondly, the study of techniques and obstacles to self-regulation of cognitive conditions of students during lecture, seminar-type training sessions, as well as during exams/tests.

\section{Methods and materials}

In order to study cognitive mental states self-regulation, a student survey was used, a method of comparative analysis of the obtained data, and a content analysis of the answers received on the methods and obstacles to using self-regulation of cognitive states during lessons.

As a part of mental state self-regulation questionnaire, students were asked to recall their cognitive states during different types of lessons: lectures, seminars, tests / exams and rate them on a scale of 1 to 10 , where 1 is the least and least experienced state, and 10 these are the most commonly experienced conditions. The list of cognitive states was highlighted by A.O. Prokhorov and M.G. Yusupov (Prokhorov \& Yusupov, 2015). Based on their research, cognitive mental states include: 1. Inspiration, 2. Thoughtfulness, 3. Reverie, 4. Interest, 5. Cognitive dissonance, 6. Curiosity, 7. Daydreaming, 8. Immunity, 9. Perplexity, 10. Stupefaction, 11. Spiritualisation, 12. Perplexity, 13. Insight, 14. Anticipation, 15. Premonition (forethought), 16. Foreboding, 17. Distraction, 18. Reflection, 19. Boredom, 20. Doubt, 21. Concentration, 22. Dullness, 23. Surprise.

It is also worth noting that among cognitive states there are positive ones, which are: inspiration, thoughtfulness, reverie, interest, curiosity, inspiration, perplexity, insight, anticipation, foreboding, thinking, reflection, concentration, surprise. There are conditions that are negative and probably reduce the effectiveness of learning activities. These are states: cognitive dissonance, daydreaming, immunity, perplexity, stupefaction, distraction, boredom, doubt, dullness. The number of cognitive states selected from the list of cognitive states most pronounced for them was not specified.

\section{Experimental base of research}

The experimental base of the research is Kazan (Volga region) Federal University. Totally, the study was attended by students of natural sciences and humanitarian areas aged 18 to 23 years in the amount of 81 people.

\section{Research stages}

The study of the problem was carried out in two stages: at the first stage, a theoretical analysis of the existing methodological approaches in the works of Russian and foreign psychologists was carried out, the problem, purpose, tasks and research methods were identified. Based on the purposes and objectives of the study, a questionnaire was prepared to study the self-regulation of students cognitive mental states during educational process.

At the second stage, an online survey of students was conducted on self-regulation of cognitive states during lessons: lectures, seminars, tests/exams. After the study was the processing of the results, analysis and preparation of practical recommendations for the implementation of the data in educational process. Steps for further research on this topic were also outlined. 


\section{RESULTS}

Processing the obtained data on the study of cognitive states during various types of educational activities (lectures, seminars, tests / exams) showed that there is a difference in the tested states of students in different types of educational classes. The results of a comparative analysis of cognitive state of students during lectures, seminars and tests / exams, the indicators of which have differences, are graphically presented in Figure 1.

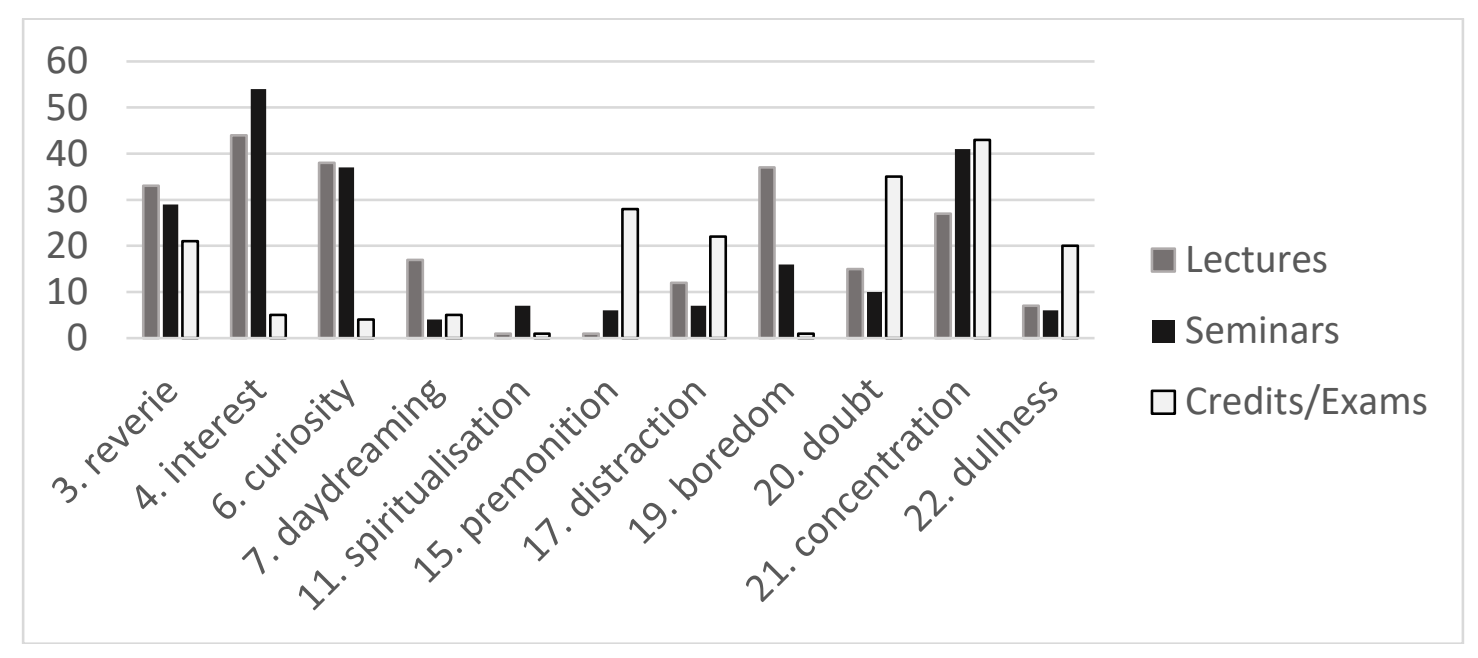

Figure 1. Students cognitive states during lectures, seminars and tests / exams, the indicators of which have differences.

According to the results of the comparative analysis, it can be concluded that at lectures, seminars and tests / exams there is a difference in students' cognitive states such as thoughtfulness, interest, curiosity, reverie, spirituality, foreboding, distraction, boredom, doubt, concentration, dullness.

Figure 1 clearly shows that during lectures, students are much more likely to be in a cognitive state of thoughtfulness, daydreaming and boredom, which indicates a certain passive position of the student during these classes. It is likely that the position of students during which they are forced to sit and listen to the lecturer impedes the assimilation of the material and allows them to mentally distance themselves from reality through conditions such as thoughtfulness, daydreaming and boredom.

As for seminars (practical classes), here one can see the predominance of cognitive mental states such as interest and spiritualization. Students are approximately equally curious in both lecture and seminar (practical) classes. Therefore, we can conclude that during seminar (practical) classes, which usually take place in an interactive form, where students themselves have the opportunity to actively participate in the process, interact with both the teacher and classmates, involvement to work and training grows. It can be assumed that the state of interest and spirituality positively affects the learning process, increasing the motivation for learning activities.

As can be seen in Figure 1 during the tests and exams, students most of all experience ineffective cognitive mental states like premonition, distraction, doubt, concentration and dullness. All of the above conditions, except for concentration, make it difficult to concentrate on the learned material in order to pass the final semester test - or pass an exam. At the same time, among students during tests/exams, conditions such as 
thoughtfulness, interest, curiosity, reverie, inspiration and boredom are manifested below all. It can be assumed that students do not have time for these conditions.

Thus, as shown in Figure 1 according to the results of a comparative analysis, students revealed differences in the tested conditions during lectures, seminars (practical) classes and tests/exams.

Next, Figure 2 shows the graphical data obtained during a survey of students on which classes they most often regulate their cognitive mental states. Six types or form of lessons were presented for selection: lecture, seminar (practical) lesson, test, exam and workshop.

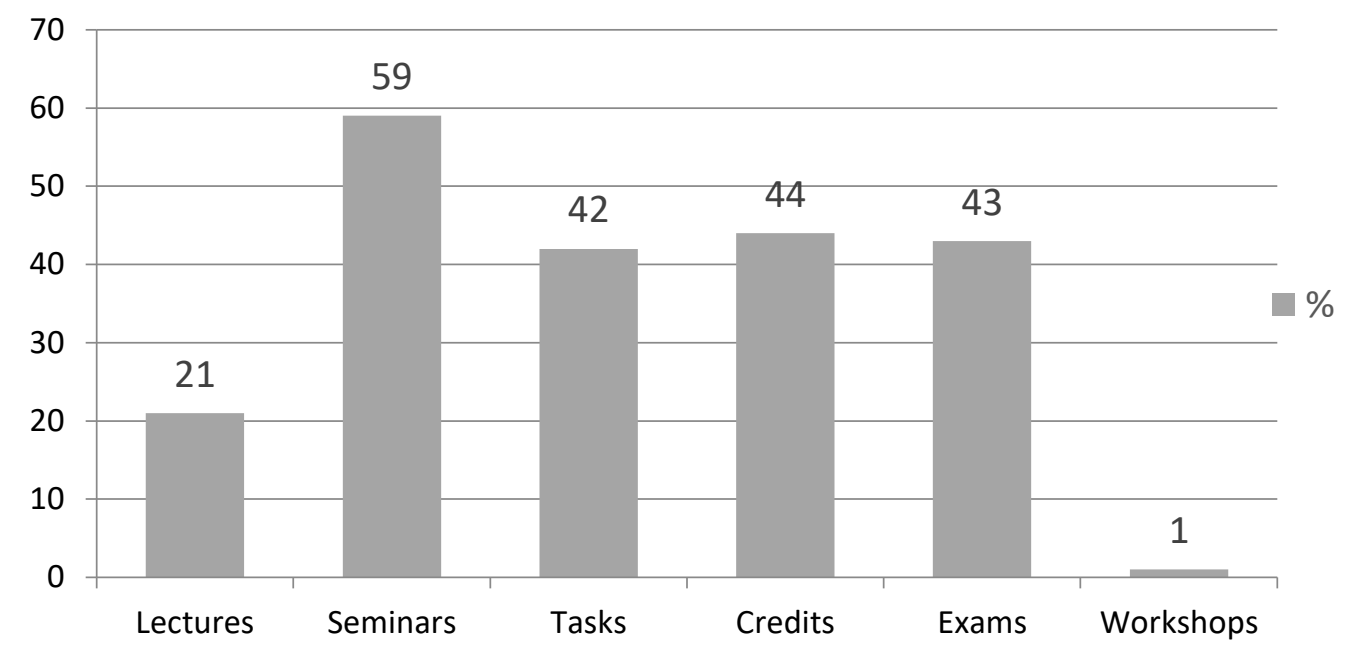

Figure 2. The results of a students' survey in during classes they most often regulate their cognitive states.

Figure 2 shows that the most often students regulate their cognitive mental states in seminar-type classes (59 students), that is, in classes where they are included in the process, they themselves are directly involved, where some action occurs and students get more practical skills. Least of all at lectures and workshops. Presumably, master classes are not so frequent, so only one student allocated him. As for lectures (21 students), here students are often least involved in the learning process, namely they are forced to sit and listen. Perhaps, given the results of the survey on the previous question, at the lectures students are in a state of reverie and boredom, which is least subject to regulation. Approximately the same number of students (42/44/43) chose the types of educational activities that imply a test of their knowledge, namely the test and credits. Most likely, situations in the educational process associated with stress and anxiety are more difficult to self-regulate. Nevertheless, many students have some techniques that help them deal with stress while assessing their knowledge by the teacher.

The following are the results of the success of students' self-regulation during training on a scale of 1 to 10 , where 1 - "I regulate my cognitive mental states very poorly", and 10 - "I perfectly regulate my mental states". The survey results showed that, in general, students highly appreciate the success of their self-regulation in the process of training. 


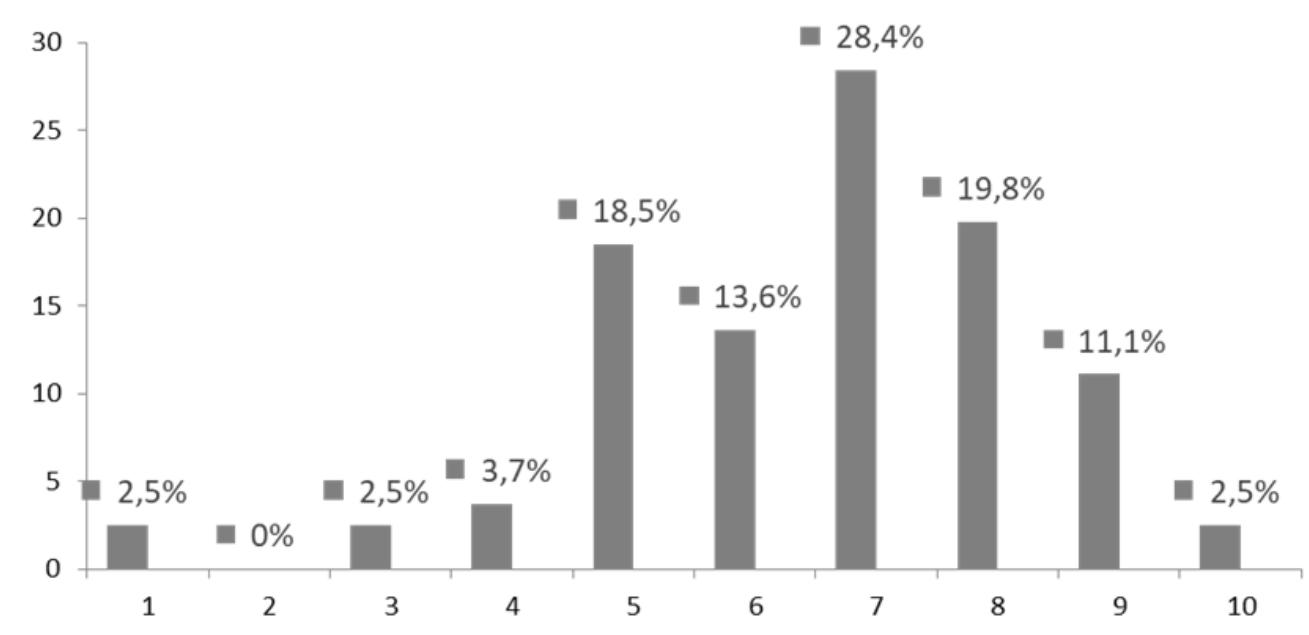

Figure 3. Evaluation of the success of students cognitive states self-regulation during lessons (on a scale of 1 to 10$)$.

As shown in Figure 3, students mainly evaluate the success of self-regulation by seven points, which indicates their sufficient knowledge in this topic, but at the same time they are still not fully managing their conditions. It is clearly seen that not all students have self-regulation techniques that allow them to carry out educational activities successfully and efficiently.

Further, the student was asked to prescribe in free form the methods and techniques for self-regulation of cognitive mental states, which they most often use during the educational process. In the course of the content analysis, various answers were obtained with techniques that could conditionally be divided into two categories: mental techniques for self-regulation of states and physical ones. The mental methods of selfregulation of cognitive states include the following: attempt to concentrate on the teacher, on the material; conscious attitude to what you are doing; take control of the situation; take control of your condition; focus on one; understanding of what is happening now; drawing and prescribing information; positive thoughts; drawing up an action plan; motivation; purposefulness, focus on the final result; self-discipline; awareness, etc. Various breathing techniques can be attributed to the physical; a break to relieve the brain; distraction, abstraction; relaxation; auto-suggestion; sports pause; write down your thoughts; listening music; memories of a successful experience; internal dialogue with oneself; an attempt to let everything drift, etc.

The analysis of the answers showed that most often students either try to take control of their condition on their own or use some kind of physical action in order to bring their condition into normal, functional and working. Based on the analysis of the answers received, we can also conclude about the variety of techniques used for self-regulation of cognitive states, that each person needs an individual approach and there is no universal technique that will help absolutely everyone.

Further, during the survey, factors that impede the process of self-regulation were identified. After the content analysis conducted on the students' answers, obstacles were identified that most often prevented students from the conscious process of self-regulation of cognitive states in the process of educational activity. Among them are especially common:

- Drowsiness, laziness, lack of concentration, fatigue;

- Procrastination; 
- Social networks, phone;

- Uninteresting, boring (boring material, lesson, teacher, etc.);

- Lack of motivation, the uselessness of the subject;

- Surroundings, empty talk, questions;

- Uncertainty, doubts;

- Stress, excitement, experience, tension, fear;

- Discontent, annoyance;

- Personal affairs, inner feelings, emotions;

- Pressure from teachers.

In this list of factors that impede the self-regulation of student mental states during the educational process, you can see how important the teacher and his own physical condition are. Perhaps this is due to the fact that students lack the skill of owning and managing personal and temporary resources.

Summing up all of the above, we can conclude that students do not have enough conscious and purposeful application of methods for self-regulation of cognitive states during learning process. The effectiveness of their educational activities depends on the student's cognitive state during the educational process, namely, when perceiving information at a lecture, seminar, test, and exam. Therefore, it is very important to teach students of different directions and specialties the technologies of mental states self-regulation during the training sessions.

The results of the study can be used in developing work programs for academic disciplines implemented within the framework of higher education, in preparing classes for lecture and seminar types, as well as in working with students to increase their effectiveness during tests and exams. The next stage is a study of the relationship of cognitive mental states and personality characteristics, metacognitive inclusion and reflexivity of students.

\section{DISCUSSIONS AND CONCLUSION}

The study of literature in psychology allows us to state the absence of special studies on the problem of the formation of the skills of the conscious use of self-regulation techniques of students' cognitive states during the educational process. However, studies of cognitive mental states as temporary states of the psyche, characterized by high activity of cognitive processes and aimed at cognizing an object or solving a particular problem, are actively considered in the works of A.O. Prokhorov, M.G. Yusupov, A.V. Chernov. The study of self-regulation of mental states has been studied and continues to be studied by A.O. Prokhorov. However, the technologies of self-regulation of students' cognitive mental states in the process of education have not yet been analysed and studied.

Thus, a study of students' cognitive states self-regulation in the educational process (lectures, seminars, tests and exams) showed that at lectures, seminars and tests / exams there is a difference in students' cognitive mental states such as thoughtfulness, interest, curiosity, reverie, spirituality, premonition, distraction, boredom, doubt, concentration, dullness.

It was found that most often students regulate their cognitive states in seminar-type classes (59 students), that is, in classes where they are included in the process, they themselves take direct part, where some action occurs and students acquire more practical skills. Least of all at lectures and master classes. 
It was found that students mainly rate the success of self-regulation quite high (by 7 points), which indicates their sufficient knowledge in this topic, but at the same time they still have not successfully cope with their conditions. According to the results of the study, it is clear that not all students have self-regulation techniques that allow them to carry out educational activities successfully and efficiently.

As for the study of self-regulation methods and obstacles that impede the implementation of these methods, here we are faced with a huge variety, which once again proves that each person, including the subject of the educational process, needs an individual approach and knowledge about the need for conscious knowledge of existing techniques self-regulation of mental states both in ordinary life situations and in the educational process.

\section{ACKNOWLEDGEMENTS}

The research was carried out with the financial support of the Russian Foundation for Basic Research, Project №19-013-00325

\section{REFERENCES}

Bodrov, V.A. (2007). Psychological mechanisms of human adaptation. In the book: L.G. Dikaya, A.L. Zhuravlev (Ed.), Psychology of adaptation and social environment: modern approaches, problems, prospects. Institute of Psychology RAS, 1, 42-67.

Dikaya, L.G. (2003). Mental self-regulation of a person's functional state. Moscow: Institute of Psychology RAS.

Hartmann, H. (2002). Ego-psychology and the problem of adaptation. New York: International Universities Press.

Konopkin, O.A. (2007). Mechanisms of conscious self-regulation of arbitrary activity of human activity. In the book: V.I. Morosanova (Eds.), Subject and personality in the psychology of self-regulation: a collection of scientific papers. Stavropol': PI RAE Publ.

Levitov, N.D. (1964). About human mental state. Moscow: Prosveshenie.

Morosanova, V.I., Fomina, T.G. \& Tsyganov, I.Yu. (2017). Conscious self-regulation and attitude to learning in achieving educational goals. St. Petersburg: Nestor-Istoriya.

Osnitsky, A.K. (2011). The development of self-regulation as a condition for the success of professional self-determination and training. In the book: V.I. Morosanova (Eds.), Psychology of self-regulation in the twenty-first century. St. Petersburg: Nestor-Istoriya.

Prokhorov, A.O. \& Larionova, I.G. (2007). Ethnocultural identity and mental states self-regulation (on the example of Russians and Tatars). Psychological Journal, 28(6), 59-68.

Prokhorov, A.O. \& Yusupov M.G. (2014a). Cognitive states in the context of students' intellectual activity. Uchenie zapiski Kazanskogo universiteta - Scientific notes of Kazan University, 6, 189-198.

Prokhorov, A.O. (2005). Functional structures and means of mental states self-regulation. Psychological Journal, 26(2), 68-80.

Prokhorov, A.O. (2017). Mental states self-regulation in everyday life of a person. Psychological research, 20(56), 7-17.

Prokhorov, A.O. \& Yusupov, M.G. (2014b). Metacognitive foundations of mental states: a situational aspect of the structurally-functional organization. Kazan: Otechestvo.

Prokhorov, A.O. \& Yusupov, M.G. (2015). Phenomenological features of various courses of study students' cognitive states. Education and self-development, 3(45), 39-46. 
Sergienko, E.A. (2009). Behavior control: individual resources of subjective regulation. Psychological Research, 5(7), 18-26.

\section{(c) $(7)(\mathrm{E})$}

This work is licensed under a Attribution-NonCommercial-NoDerivatives 4.0 International (CC BY-NC-ND 4.0). 